\title{
Effect of myrrh and thyme on Trichinella spiralis enteral and parenteral phases with inducible nitric oxide expression in mice
}

\author{
Rasha AH Attia ${ }^{1 /+}$, Abeer E Mahmoud', Haiam Mohammed Mahmoud Farrag', \\ Rania Makboul'2, Mona Embarek Mohamed ${ }^{3}$, Zedan Ibraheim ${ }^{4}$
}

\footnotetext{
${ }^{1}$ Assiut University, Faculty of Medicine, Department of Parasitology, Assiut, Egypt ${ }^{2}$ Assiut University, Faculty of Medicine, Department of Pathology, Assiut, Egypt ${ }^{3}$ Assiut University, Faculty of Medicine, Department of Microbiology and Immunology, Assiut, Egypt ${ }^{4}$ Assiut University, Faculty of Pharmacy, Department of Pharmacognosy, Assiut, Egypt
}

Trichinellosis is a serious disease with no satisfactory treatment. We aimed to assess the effect of myrrh (Commiphora molmol) and, for the first time, thyme (Thymus vulgaris L.) against enteral and encysted (parenteral) phases of Trichinella spiralis in mice compared with albendazole, and detect their effect on inducible nitric oxide synthase (iNOS) expression. Oral administration of $500 \mathrm{mg} / \mathrm{kg}$ of myrrh and thyme led to adult reduction $(90.9 \%, 79.4 \%)$, while 1,000 $\mathrm{mg} / \mathrm{kg}$ led to larvae reduction $(79.6 \%, 71.3 \%)$, respectively. Administration of $50 \mathrm{mg} / \mathrm{kg}$ of albendazole resulted in adult and larvae reduction $(94.2 \%, 90.9 \%)$. Positive immunostaining of inflammatory cells infiltrating intestinal mисоsa and submucosa of all treated groups was detected. Myrrh-treated mice showed the highest iNOS expression followed by albendazole, then thyme. On the other hand, both myrrh and thyme-treated groups showed stronger iNOS expression of inflammatory cells infiltrating and surrounding encapsulated T. spiralis larvae than albendazole treated group. In conclusion, myrrh and thyme extracts are highly effective against both phases of T. spiralis and showed strong iNOS expressions, especially myrrh which could be a promising alternative drug. This experiment provides a basis for further exploration of this plant by isolation and retesting the active principles of both extracts against different stages of $\mathrm{T}$. spiralis.

Key words: Trichinella spiralis - albendazole - thyme - myrrh - iNOS - enteral, parenteral phases cytotoxicity tests - limulus amoebocyte lysate assay

Trichinellosis is a world-wide important parasitic zoonosis with global distribution. The different cultural eating habits represent the main factor of human infections which mainly occur through ingestion of infective larvae in undercooked pork products (Pozio 2007).

All stages of development of Trichinella spiralis, adult, migratory, and encysted stages are found in the same host and it infects a wide variety of mammalian hosts, so this parasite has been commonly used as an experimental model to estimate the effect of many anthelmintic agents (Yadav \& Temjenmongla 2006).

Albendazole and mebendazole are the principal anthelmintic drugs for the treatment of trichinellosis (Gottstein et al. 2009). However, they have limited bioavailability, a high degree of resistance, and weak activity against encapsulated larvae (Caner et al. 2008). Furthermore, some of these drugs are contraindicated in pregnancy and children under three years (Yadav \& Temjenmongla 2012), while others are thought to be carcinogenic (Shalaby et al. 2010). So, there is an intense need for safe and effective antitrichinellosis drugs, especially those from natural agents (Yadav \& Temjenmon-

doi: 10.1590/0074-02760150295

+ Corresponding author: rashaattia@gmail.com

Received 6 August 2015

Accepted 6 November 2015 gla 2012), as they have less toxicity and are free from adverse effects (Basyoni \& El-Sabaa 2013).

Myrrh is derived from the stem of different Commiphora molmol and contains volatile oil, resin, and gum. It is one of the most widely used plants in traditional medicine as an effective analgesic, antipyretic, antibacterial, and antifungal (Dolara et al. 2000). It has fasciolocidal, schistosomicidal, insecticidal, molluscicidal activities, and a potent activity against both intestinal and muscular stages of T. spiralis (Basyoni \& El-Sabaa 2013).

Thyme (Thymus vulgaris) is one of the popular culinary herbs in southern Europe and Mediterranean regions. Thymol is a natural compound isolated from thyme. It has antiseptic, antifungal, and strong antibacterial activities (Dorman \& Deans 2000, Mathela et al. 2010). It also has a powerful antioxidant activity (Ündeğer et al. 2009, Ahmad et al. 2010, Zarrini et al. 2010). Thyme was found to have a significant antiparasitic effect against bird protozoan, Trichomonas gallinae (Nasrabadi et al. 2012), and in vitro scolicidal effects (Moazeni et al. 2012).

Nitric oxide (NO) is produced from arginine by inducible NO synthase (iNOS) from activated T-cells. It is one of the secretory products of macrophages which contribute to the host defense function. It kills or at least suppresses many parasites, Trypanosoma cruzi, Plasmodium, Leishmania major, Schistosoma, and Toxoplasma gondii (Ascenzi \& Gradoni 2002, Boczon' et al. 2004). During the intestinal phase of T. spiralis infection, NO plays a minor role in the expulsion of $T$. spiralis adults; however, it essentially participates in intestinal pathology (Boczon' et al. 2004). During the muscular phase many structural and biochemical changes occur 
in muscles which are regulated by oxygen and nitrogen free radicals generated by both the host and the parasite. These free radicals can combine with NO to form peroxynitrate, which leads to injury or death of the muscle fibres. This induced iNOS activity in the skeletal muscle of T. spiralis-infected mice may participate in the host's biochemical defense mechanism (Boczon' \& Wargin 2000, Boczon' et al. 2002, 2004).

The present study aimed at investigating the effect of myrrh and thyme extracts on both the intestinal and muscular phases of T. spiralis infection in mice in comparison with albendazole (reference drug). It also aimed at studying the iNOS expression following treatment by each drug during both phases of infection and discussing its relevance to the pathology of the parasite and defense mechanisms of the infected host.

\section{MATERIALS AND METHODS}

Experimental animals and model - One hundred and thirty parasitic free BALB/c mice (25-30 g) aged sixeight weeks were used. They were obtained from the Faculty of Medicine, Assiut University, Assiut, Egypt, and maintained under controlled light and temperature with standard diet and water supplies. One hundred and twenty of them were infected orally with about 300 larvae per mouse while the remaining 10 were kept as the noninfected nontreated control group. The strain of $T$. spiralis used was originally isolated from the diaphragms of infected pigs obtained from El-Bassatine Abattoir, Cairo. It had been routinely maintained in the laboratory of the Faculty of Medicine, Assiut University, by consecutive passage through BALB/c mice following the method described by Gamble (1996). Briefly, the heavily infected diaphragms of the pigs were minced and digested in $1 \%$ pepsin-hydrochloride. After overnight incubation at $37^{\circ} \mathrm{C}$, larvae were collected using the sedimentation technique, washed in physiological saline $(0.85 \%)$ several times, and the number of larvae per $\mathrm{mL}$ was counted.

Reference drug - Albendazole was supplied as suspension, $20 \mathrm{mg} / \mathrm{mL}$, from the Egyptian International Pharmaceutical Industries Co.

Plant materials and preparation of extracts - The aerial parts of $T$. vulgaris L. (thyme), family Limiaceae $(1,000 \mathrm{~g})$ were collected from the botanical garden of the Faculty of Pharmacy, Assiut University, during June 2014, then identified by Dr Zidan Ibrahim, Professor of Pharmacognosy, Faculty of Pharmacy, Assiut University. It consists of volatile oil $(1.2 \% \mathrm{v} / \mathrm{w})$ with phenol value not less than $0.5 \%$ expressed as thymol. The phenols in the isolated oil are determined by reaction with aminopyrazolone and potassium ferricyanide in ammonical solution with subsequent measurement of absorbance at $450 \mathrm{~nm}$ (Evans 2002). The plant was shade dried, crushed, sieved, and kept till use. A voucher specimen was deposited in the Botanical Museum, Faculty of Pharmacy, Assiut University. A $500 \mathrm{~g}$ of the shade-dried powdered aerial parts of the thyme was extracted with $70 \%$ ethanol by maceration and percolation for $24 \mathrm{~h}$. The extraction process was repeated twice. The alcohol extracts of the plant were pooled together and evaporated under reduced pressure at $45^{\circ} \mathrm{C}$ till they were free from the solvent. The solvent-free residue was weighed to give $8.76 \mathrm{~g}$ (yield, $17.52 \%$ ). The dried extract was stored at $+4^{\circ} \mathrm{C}$ till use. Myrrh is oleo-gum resin (C. molmol) family Burseraceae. Its import from Sudan exudes naturally or from incisions made in bark. It contains $7-17 \%$ volatile oil, $25-40 \%$ resin, $57-61 \%$ gum, and 3-4\% impurities. It was purchased from the local market in Assiut Governorate, crushed to fine powder and sieved. Ten grams of the plant material were suspended in $100 \mathrm{~mL}$ distilled water with the aid of 3\% Tween 80 and kept in the refrigerator till use. Chemical tests give yellowish emulsion when triturated with water, and when extracted with $90 \%$ alcohol a whitish mass of gum and impurities remains (Evans 2002).

Cytotoxicity assays (CTAs) on tissue culture cells CTAs were performed on mouse fibroblast cell BALB/c 3T3 (VACSERA, Egypt) supplemented with $10 \%$ bovine calf serum, $4 \mathrm{mM}$ L-glutamine, $100 \mathrm{IU}$ penicillin, and $100 \mu \mathrm{g} / \mathrm{mL}$ streptomycin (Bioanalyse, Turkey) using the neutral red uptake assay (Repetto et al. 2008).

Evaluation of microbial contamination and endotoxin production - Total aerobic microbial count and total combined yeasts/moulds count were used for quantitative enumeration of mesophilic bacteria or fungi that may grow under aerobic conditions in our herbal products using the pour plating technique (EDQM Council of Europe 2014).

The bacterial endotoxin test was performed by the limulus amoebocyte lysate assay (gel-clot technique) as reported (Hussaini \& Hassanali 1987).

Study design groups of animals - Infected mice were classified into four main groups; A, B, C, and D. Each group had 30 mice. Group A was infected and left untreated as a control group while groups B, C, and D received oral doses of albendazole, thyme, and myrrh, respectively.

Dose schedule - Each main group of the treated animals was subdivided into three subgroups (I, II, and III), each subgroup having 10 mice. Animals of subgroup I of group $\mathrm{B}, \mathrm{C}$, and D received $50 \mathrm{mg} / \mathrm{kg}$ albendazole, $500 \mathrm{mg} / \mathrm{kg}$ thyme, and $500 \mathrm{mg} / \mathrm{kg}$ myrrh, respectively, starting from the third day post-infection (dpi) for three successive days (Shoheib et al. 2006). They were sacrificed on the seventh dpi to evaluate the effects of the drugs against adult worms (intestinal phase). The numbers of adult worms in the gut were isolated and counted (Denham \& Martinez 1970). Animals of subgroups II and III of group B, C, and D received $50 \mathrm{mg} / \mathrm{kg}$ albendazole, $1,000 \mathrm{mg} / \mathrm{kg}$ thyme, and $1,000 \mathrm{mg} / \mathrm{kg}$ myrrh, respectively, starting from the 31st dpi for seven successive days. Mice from subgroup II were sacrificed on the 49th dpi (Yadav \& Temjenmongla 2012) to evaluate the effects of the drugs against the larvae and count them (Goettsch et al. 1994). Mice from subgroup III were sacrificed on the 60th dpi (Caner et al. 2008). The infected, nontreated control group (group A) was subdivided into five subgroups (6 mice each). Each subgroup was sacrificed on the seventh, 21st, 30th, 49th, and 60th dpi, respectively. For histopathological and immunohistochemical evaluation, intestinal specimens were 
taken from sacrificed mice on the seventh dpi, while muscular specimens were taken from sacrificed mice on the 21st, 30th, 49th, and 60th dpi, respectively.

Histopathological examination - Intestinal specimens $(1 \mathrm{~cm}$ from the small intestine at the junction of the proximal 1/3 and distal 2/3) (Nassef et al. 2010) were taken from mice sacrificed on the seventh dpi, while skeletal muscle specimens from the hind legs were taken from mice sacrificed on the 21st, 30th, 49th, and 60 dpi (Zeromski et al. 2005, Monib et al. 2010). These specimens were fixed in $10 \%$ formaline, dehydrated, cleared, and then embedded in paraffin blocks. Paraffin sections were taken of $5 \mu \mathrm{m}$ thickness and stained by haematoxylin and eosin and examined microscopically (Shalaby et al. 2010).

Evaluation of iNOS expression during the course of infection - The presence of iNOS protein was analysed by immunohistochemical staining using the avidin biotin immunoperoxidase complex technique (Ultravision Plus Detection System antipolyvalent HRP/DAB, ready to use; Thermo Scientific Corporation, USA). Immunohistochemistry was performed according to the manufacturing protocol. Tissue sections $(4-\mu \mathrm{m}$ thick) of the previously formalin-fixed, paraffin-embedded specimens were cut and mounted. The sections were de-paraffinised and rehydrated in graded alcohol, and endogenous peroxidase was blocked by the use of 3\% hydrogen peroxide in methanol for $5 \mathrm{~min}$. For antigen retrieval the slides were immersed in a citrate puffer and put in the microwave for $8 \mathrm{~min}$. The samples were then incubated for $1 \mathrm{~h}$ at room temperature with iNOS (Rabbit Polyclonal Antibody; Thermo Scientific Corporation) at a dilution of 1:100. After the application of a secondary antibody, slides were developed using 3-3'-diaminobenzidine chromogen and counterstained with haematoxylin. Negative control slides were made by omitting the primary antibody. Sections from the lung were stained as a positive control.

Evaluation of immunohistochemistry - Cytoplasmic NO expression was evaluated by counting positive cells in 10 high power fields in well-labelled areas as deter- mined at low magnification (the most densely labelled areas) and expressed in percentage.

Statistical analysis - The collected data were analysed by Statistical Package for Social Sciences v. 20 for Windows. All values were expressed as mean \pm standard deviation. The significance of differences between the groups was calculated using the ANOVA test. The percentage of reduction was calculated between the treated groups and the control groups. The significance of differences between the groups was calculated using Student's $t$ test. p-value of $<0.05$ was considered statistically significant.

Ethics - The experimental animal studies were conducted in accordance with the international valid guidelines and were maintained under convenient conditions at the Animal House, Faculty of Medicine, Assiut University.

\section{RESULTS}

The CTAs - The optical density (OD) ${ }_{540}$ of each test article was compared with the mean value $\mathrm{OD}_{540}$ for the negative control. Our herbal extracts fulfilled the mentioned acceptance criteria. Cell viabilities were $>70 \%$ relative to the negative control for thyme and myrrh at their highest concentrations.

Effects of albendazole, thyme, and myrrh against adult worms - A significant decrease in the mean number of adult worms was obtained in all treated groups $(\mathrm{p}<0.01)$. The least count was found in group B which received albendazole with efficacy of $94.2 \%$ followed by group D which received myrrh with efficacy of $90.3 \%$. The least reduction in the number of adult worms was observed in thyme-treated group (group C) with efficacy of $79.4 \%$ (Table).

Effects of albendazole, thyme, and myrrh against encysted larvae - A significant decrease in the mean larval count was detected in all treated groups $(\mathrm{p}<0.01)$. The best reduction of larval count was found in group B which received albendazole with efficacy of $90.9 \%$, followed by group D which received myrrh with effica-

TABLE

Efficacy (as percentage reduction) of albendazole, thyme, and myrrh against adult and encysted stages of Trichinella spiralis

\begin{tabular}{lcccc}
\hline & Intestinal worm & Count/mouse & Muscle larval & Count/mouse \\
\cline { 2 - 5 } Studied groups & Mean \pm SD (range) & $\begin{array}{c}\text { Efficacy } \\
\text { (\% reduction) }\end{array}$ & Mean \pm SD (range) & $\begin{array}{c}\text { Efficacy } \\
(\% \text { reduction) }\end{array}$ \\
\hline $\begin{array}{l}\text { A } \\
\text { (infected, nontreated) }\end{array}$ & $31.0 \pm 1.6(29-33)$ & 0 & $2007.9(190-210)$ & 0 \\
$\begin{array}{l}\text { B } \\
\text { (albendazole) }\end{array}$ & $1.8 \pm 0.84^{a}(1-3)$ & 94.2 & $18.2 \pm 2.9^{a}(15-22)$ & 90.9 \\
$\begin{array}{l}\text { C } \\
\text { (thyme) } \\
\text { D } \\
\text { (myrrh) }\end{array}$ & $6.4 \pm 1.5^{a}(4-8)$ & 79.4 & $57.4 \pm 4.9^{a}(50-62)$ & 71.3 \\
\hline
\end{tabular}

$a$ : statistically significant at $\mathrm{p}<0.01$; SD: standard deviation. 
cy of $79.6 \%$. The least reduction was detected in group $\mathrm{C}$ which received thyme with efficacy of $71.3 \%$ (Table).

Histopathological effects - No histopathological changes were observed in both the intestinal and muscular sections of the noninfected, nontreated control group.

Intestinal sections of group A (infected nontreated) on the seventh dpi revealed the presence of adult worm sections within the mucosa together with chronic inflammatory cells infiltrating the mucosa and submucosa. Intestinal sections of treated groups, compared with group $\mathrm{A}$, revealed a marked decrease in inflammatory infiltrate in group B while mild to moderate cellular infiltration was observed in groups $\mathrm{C}$ and $\mathrm{D}$.

Muscular sections on the 21st, 30th, 49th, and 60th dpi of group A (infected, nontreated) revealed the presence of a massive number of encysted $T$. spiralis larvae diffusely present in muscles sarcoplasm (Fig. 1A) and a massive number of chronic inflammatory cells in the form of lymphocytes, plasma cells, eosinophils, and histiocytes infiltrating muscle bundles and surrounding the encysted larvae.

On the 49th and 60th dpi, pathological changes in the muscular sections of group $\mathrm{C}$ which received thyme showed a fewer number of encysted larvae than the infected, nontreated group with heavier inflammatory cellular infiltration surrounding them. The capsule in most of the larvae appeared thick and complete (Fig. 1B), while in groups $\mathrm{B}$ and $\mathrm{D}$ which received albendazole and myrrh, respectively, the muscular sections showed much fewer numbers of encysted larvae, most of them showed degenerative changes, areas of thinning and splitting of the capsule into thin layers, areas of breakdown, vacuolization and invasion by inflammatory cellular infiltrate. These changes were more evident in group D (Fig. 1C, D).

Expression of iNOS producing cells - Cytoplasmic iNOS expression was detected in chronic inflammatory cells (lymphocytes, plasma cells, and macrophages). No positive iNOS expression could be seen in the intestine or the muscle of the noninfected nontreated control group.

On day 7, iNOS expression was evident in the inflammatory cells infiltrating the mucosa and submucosa of the intestine. In comparison with group A (infected, nontreated), the highest expression was detected in group D (myrrh) followed by group B (albendazole) while group C (thyme) showed expression nearly equal to group A.

During the muscular phase, iNOS expression in group A (infected, nontreated mice) was distinct from the 21th up to the 60th dpi in almost all infiltrating cells between muscle bundles and surrounding the encapsulated larvae (Fig. 2A). The highest iNOS expression was detected on the 21st and 60th dpi.

At the 49th and 60th dpi, high iNOS expression was detected in all treated groups including group B (albendazole) (Fig. 2B) in comparison with group A. This effect was more evident in group $C$ (thyme) on day 49 (Fig. $2 \mathrm{C}$ ), and in group D (myrrh) on the 60th dpi (Fig. 2D).

\section{DISCUSSION}

Some recent studies suggest that there could be a good extent in finding some alternative drug compounds from medicinal plants for an effective management of $T$.
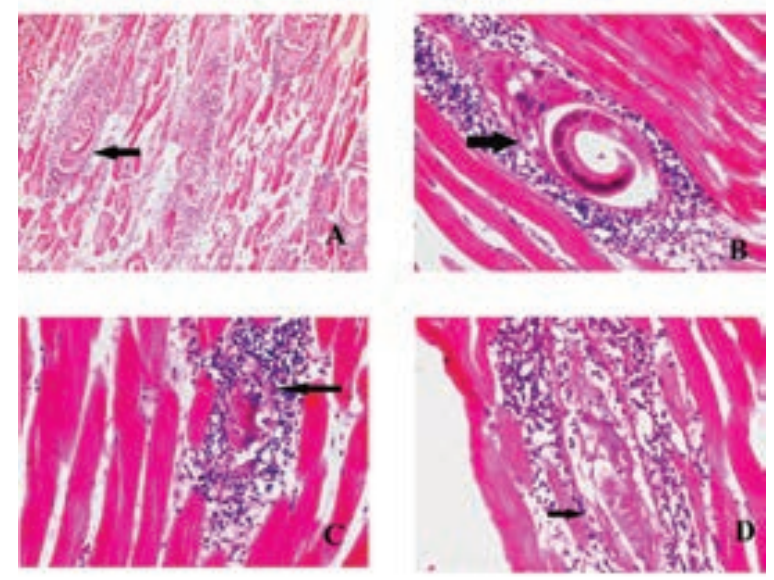

Fig. 1: skeletal muscle sections of Trichinella spiralis infected mice stained by haematoxylin and eosin. A: day 30 of infected nontreated group showing multiple encysted larvae surrounded by intense inflammatory cellular infiltrate $(200 \mathrm{X})$; B: thyme treated group $(1,000$ $\mathrm{mg} / \mathrm{kg}$ ) at day 49 showing encysted larvae surrounded by thick intact capsule and intense inflammatory cellular infiltrate (400X); C: albendazole treated groups $(50 \mathrm{mg} / \mathrm{kg})$ at day 49 showing homogenised larvae, vacuolation and splitting of the capsule into thin layers (arrow) with diffuse inflammatory cellular infiltration surrounding and invading the capsule (arrow) (400X); D: myrrh treated group (1,000 $\mathrm{mg} / \mathrm{kg}$ ) at day 49 post-infection showing homogenised larvae with broken down incomplete capsule which is completely invaded and surrounded by inflammatory cells (400X).
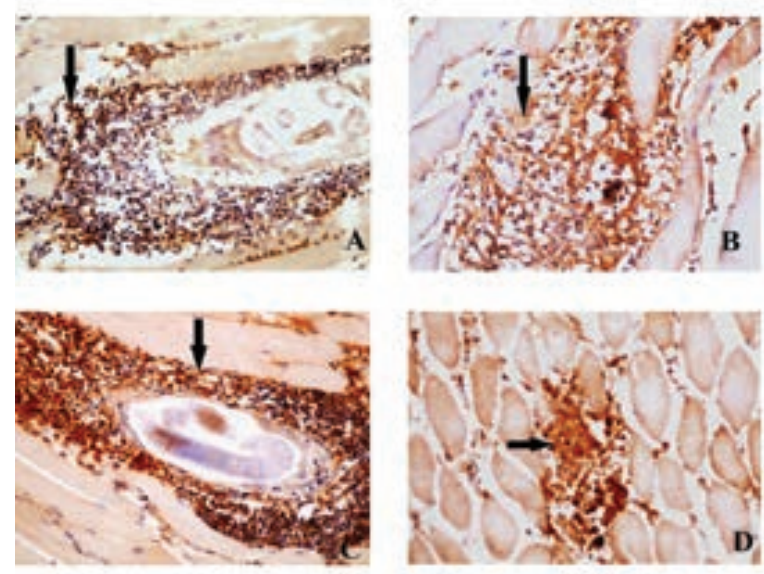

Fig. 2: immunohistochemistry sections of skeletal muscle from infected mice using antiinducible NO synthase (iNOS) antibody. A: infected nontreated group at day 30 showing positive immunostaining of the cellular infiltrates surrounding encysted larvae (400X); B: albendazole treated groups $(50 \mathrm{mg} / \mathrm{kg})$ at day 49 showing strong immunostained inflammatory cells surrounding encysted larvae (400X); C: thyme treated group $(1,000 \mathrm{mg} / \mathrm{kg})$ at day 49 showing very strong iNOS expression of the cellular infiltrates surrounding the larvae (400X); D: myrrh treated group $(1,000 \mathrm{mg} / \mathrm{kg})$ at day 60 showing strong immunostained inflammatory cells infiltrating the muscle bundles (400X).

spiralis infection (Abu El Ezz 2005, Caner et al. 2008, Shalaby et al. 2010). The present study assessed the effectiveness of myrrh and thyme extracts against different stages of $T$. spiralis in mice compared with the common commercial drug albendazole. The microbial limit 
of our herbal extracts was within an acceptable range that does not pose health hazards to intended groups or diminish herbal stability (Moreira et al. 2014).

The present results showed a significant decrease in the mean number of adults and larvae in all treated groups. Albendazole showed the highest efficacy against both the intestinal and muscular stages followed by myrrh, while thyme had the least efficacy.

In the present study, albendazole-treated mice were given $50 \mathrm{mg} / \mathrm{kg}$ for three successive days starting from the third dpi, which revealed a significant reduction $(94.2 \%)$ in the numbers of adult worms. Similar efficacies of albendazole and mebendazole, which is another benzimidazole derivative, were reported by previous studies (Chung et al. 2001, Siriyasatien et al. 2003, Yadav \& Temjenmongla 2006, Shalaby et al. 2010). Also a significant reduction (efficacy of $90.9 \%$ ) was revealed when albendazole-treated mice were given the same dose for seven successive days starting from the 31st dpi. Similar efficacy of mebendazole was reported (Yadav \& Temjenmongla 2006). However, much lower efficacies of albendazole against encysted muscle larvae were reported by previous studies (Chung et al. 2001, Siriyasatien et al. 2003, Shoheib et al. 2006, Shalaby et al. 2010). The differences in the efficacy of albendazole against both the intestinal and muscular stages depend on the time, dose, and duration of treatment (Siriyasatien et al. 2003).

A dose of $500 \mathrm{mg} / \mathrm{kg}$ myrrh given for three successive days (intestinal phase) and $1,000 \mathrm{mg} / \mathrm{kg}$ for seven successive days (muscular phase) produced efficacy of $90.3 \%$ against adult worms, which was almost comparable with that of albendazole (94.2\%), while it decreased to $79.6 \%$ against muscle larvae. To our knowledge, only one publication that proved the effectiveness of myrrh against $T$. spiralis has been reported (Basyoni \& El-Sabaa 2013). The differences in results might be due to the different doses and schedules.

Besides the potent insecticidal and molluscicidal activities of myrrh (Basyoni \& El-Sabaa 2013), it proved efficacious in the treatment of patients with chronic fascioliasis with no observed adverse effects or toxicity (Massoud et al. 2001). It induced a cure rate of $98.09 \%$ in schistosomiasis patients with transient side effects (Sheir et al. 2001).

In the present study, thyme efficacy was $79.4 \%$ against adult worms (dose of $500 \mathrm{mg} / \mathrm{kg}$ ) while its efficacy was $71.3 \%$ for encysted larvae (dose of $1,000 \mathrm{mg} /$ $\mathrm{kg}$ ). To our knowledge, no available published literature on thyme (T. vulgaris) investigates its anti-Trichinella activity, but it has potent scolicidal effects (Moazeni et al. 2012), and showed different significant antiparasitic effects (Mikus et al. 2000, Santoro et al. 2007, Nasrabadiet al. 2012). In general, the efficacy of both plant extracts against encysted larvae was relatively low compared with the adult stage. This may be accounted for by the fact that once the Trichinella larvae have become encysted in muscle tissues, therapeutic intervention is generally less feasible as the susceptibility of the cyst to chemotherapeutic agents diminishes with the duration of infection (Yadav \& Temjenmongla 2006, 2012).
There are many studies which have investigated the effect of different plant extracts against $T$. spiralis in experimental animals (Abu El Ezz 2005, Yadav \& Temjenmongla 2006, 2012, Caner et al. 2008, Shalaby et al. 2010). The efficacies of both plant extracts used in this study were higher than those of previous studies. This may be attributed to the use of high doses and early administration of the extracts during both the intestinal and muscular phases for many successive days.

In this study, histopathological examination of group $\mathrm{C}$ (thyme) was similar to that of group A (infected, nontreated) while the mice of groups $\mathrm{B}$ and $\mathrm{D}$ which received albendazole and myrrh, respectively, showed degeneration of most encysted larvae with splitting, vacuolation, and damage to their capsule combined with diffuse cellular infiltration.

In the present study, iNOS expression on the seventh dpi showed positive inflammatory cells infiltrating the mucosa and submucosa of the intestine of all infected groups. Group D (myrrh) showed the highest expression followed by group B (albendazole) while group C (thyme) and group A (infected, nontreated) showed nearly the same expression. These iNOS expressions, together with the results of drug efficacy for adult expulsion from the intestine, reinforce previous findings which indicated that NO synthesised by iNOS is not essential for the expulsion of T. spiralis adults from mice; however, they play a crucial role in the induction of the T-helper 2-mediated severe enteropathy that accompanies the intestinal phase (Lawrence et al. 2000, Abd El Aal et al. 2003, Boczon' et al. 2004).

The results of the present study showed positive iNOS expression in nearly all cells infiltrating infected muscles from the 21st up to 60th dpi in group A (infected, nontreated). The highest expression was on the 21st and 60 th dpi. This result confirms the idea of the increase of iNOS expression in the muscles on day 21 and additionally on 70th dpi (Boczon' \& Wargin 2000, Boczon' et al. 2004). Consistent with Zeromski et al. (2005), strong iNOS expression could be seen in the inflammatory cells infiltrating and surrounding encapsulated T. spiralis larvae in infected muscles after albendazole treatment. These results confirm previous biochemical data which reported that albendazole treatment during experimental trichinellosis resulted in the stimulation of iNOS expression. Both thyme and myrrh-treated groups (groups C and D) showed even stronger iNOS expression which may be due to their reported powerful antioxidant activities (Ündeğer et al. 2009, Ahmad et al. 2010, Zarrini et al. 2010, Fathy 2011). Also the inflammatory cells surrounding the encysted larvae produce high levels of reactive oxygen species, including $\mathrm{NO}$ and other free radicals (Bruschi \& Lucchi 2001).

Consistent with Boczon' et al. (2004), Kołodziej-Sobocińska et al. (2007), and Issa et al. (2008), iNOS expression in the present study lasted until the end of the study (60th dpi), which may indicate the protective role of iNOS against early infection (intestinal phase) and encysting larvae (Issa et al. 2008). Expression of iNOS and its impact on the pathology of infected tissue have been found in some other tissue parasites (Jarillo-Luna et al. 2002, Clark et al. 2003, Long et al. 2004). 
The results of the present study showed that myrrh and thyme extracts were both effective against both the intestinal and muscular stages of T. spiralis, especially myrrh with results nearly comparable to those achieved by albendazole. Both myrrh and thyme extracts showed higher iNOS expression in comparison with albendazole which may effectively modulate the pathological response, immune and defense mechanisms of the infected host. The active principles of both extracts should be isolated and retested against different stages of $T$. spiralis.

\section{REFERENCES}

Abd El Aal AA, EI-Arousy M, lssa RM 2003. Nitric oxide release during experimental schistosomiasis and trichinellosis. Egypt $J$ Med Sci 24: 343-354.

Abu El Ezz NM 2005. Effect of Nigella sativa and Allium cepa oils on Trichinella spiralis in experimentally infected rats. J Egypt Soc Parasitol 35: 511-523.

Ahmad A, Khan A, Yousuf S, Khan LA, Manzoor N 2010. Proton translocating ATPase mediated fungicidal activity of eugenol and thymol. Fitoterapia 81: 1157-1162.

Ascenzi P, Gradoni L 2002. Nitric oxide limits parasite development in vectors and in invertebrate intermediate hosts. IUMBM Life 53: $121-123$.

Basyoni MM, El-Sabaa AA 2013. Therapeutic potential of myrrh and ivermectin against experimental Trichinella spiralis infection in mice. Korean J Parasitol 51: 297-304.

Boczon’ K, Wandurska-Nowak E, Wierzbicki A, Frydrychowicz M, Mozer-Lisewska I, Zeromski J 2004. mRNA expression and immunohistochemical localization of inducible nitric oxide synthase (NOS-2) in the muscular niche of Trichinella spiralis. Folia Histochem Cytobiol 42: 209-213.

Boczon' K, Wandurska-Nowak E, Szulc M 2002. The effect of albendazole on iNOS-derived NO production in experimental trichinellosis. Helminthol 39: 17-21.

Boczon' K, Wargin B 2000. Inducible nitric oxide synthase in the muscles of Trichinella sp. infected mice treated with glucocorticoid methylprednisolone. Comp Parasitol 67: 230-235.

Bruschi F, Lucchi NW 2001. Enzymatic antioxidant systems in helminth parasites: no doubt on their evasive role. Acta Parasitol 46: 233-241.

Caner A, Döşkaya M, Değirmenci A, Can H, Baykan S, Uner A, Başdemir G, Zeybek U, Gürüz Y 2008. Comparison of the effects of Artemisia vulgaris and Artemisia absinthium growing in western Anatolia against trichinellosis (Trichinella spiralis) in rats. Exp Parasitol 119: 173-179.

Chung MS, Joo KH, Quan FS, Kwon HS, Cho SW 2001. Efficacy of flubendazole and albendazole against Trichinella spiralis in mice. Parasite 8 (Suppl. 2): S195-S198.

Clark IA, Awburn MM, Whitten RO, Harper CG, Liomba NG, Molyneux ME, Taylor TE 2003. Tissue distribution of migration inhibitory factor and inducible nitric oxide synthase in falciparum malaria and sepsis in African children. Malar J 2-6: 1-17.

Denham DA, Martinez AR 1970. Studies with methyridine and Trichinella spiralis. 2 . The use of drugs to study the rate of larval production in mice. J Helminthol 44: 357-363.

Dolara P, Corte B, Ghelardini C, Pugliese AM, Cerbai E, Menichetti S, Lo Nostro A 2000. Local anaesthetic and antifungal properties of sesquiterpenes from myrrh. Planta Med 66: 356-358.
Dorman HJ, Deans SG 2000. Antimicrobial agents from plants: antibacterial activity of plant volatile oils. $J$ Appl Microbiol 88: 308-316.

EDQM Council of Europe 2014. European Pharmacopoeia. Available from: edqm.eu/en/european-pharmacopoeia-8th-edition-1563.html

Evans WC 2002. Trease \& Evans' Pharmacognosy, 15th ed., Elsevier, Edinburgh, $585 \mathrm{pp}$.

Fathy FM 2011. Effect of mirazid (Commiphora molmol) on experimental giardiasis. J Egypt Soc Parasitol 41: 155-177.

Gamble HR 1996. Detection of trichinellosis in pigs by artificial digestion and enzyme immunoassay. J Food Prot 59: 295-298.

Goettsch W, Garssen J, Deijns A, De Gruijl FR, Van Loveren H 1994. UV-B exposure impairs resistance to infection by Trichinella spiralis. Environ Health Perspect 102: 298-301.

Gottstein B, Pozio E, Nöckler K 2009. Epidemiology, diagnosis, treatment, and control of trichinellosis. Clin Microbiol Rev 22: 127-145.

Hussaini SN, Hassanali HT 1987. Limulus amoebocyte lysate assay of endotoxin: a method for visual detection of the positive gel reaction. J Med Microbiol 24: 89-90.

Issa RM, Shalaby MA, Sabry HY, Hagag SH 2008. Estimation of nitric oxide level in mice infected by Trichinella spiralis. PUJ 1: 137-143.

Jarillo-Luna RA, Campos-Rodríguez R, Tsutsumi V 2002. Entamoeba histolytica: immunohistochemical study of hepatic amoebiasis in mouse. Neutrophils and nitric oxide as possible factors of resistance. Exp Parasitol 101: 40-56.

Kołodziej-Sobocińska M, Dvoroznakova E, Dziemian E, Machnicka-Rowińska B 2007. Trichinella spiralis reinfection: macrophage activity in BALB/c mice. Parasitol Res 101: 629-637.

Lawrence CE, Paterson JC, Wei XQ, Liew FY, Garside P, Kennedy MW 2000. Nitric oxide mediates intestinal pathology but not immune expulsion during Trichinella spiralis infection in mice. $J$ Immunol 164: 4229-4234.

Long XC, Li YL, Ruppel A 2004. Expression of inducible nitric oxide synthase in the livers of mice infected with Schistosoma japonicum. Zhongguo Ji Sheng Chong Xue Yu Ji Sheng Chong Bing Za Zhi 22: 157-159.

Massoud A, EL Sisi S, Salama O, Massoud A 2001. Preliminary study of therapeutic efficacy of a new fasciolicidal drug derived from Commiphora molmol (myrrh). Am J Trop Med Hyg 65: 96-99.

Mathela CS, Singh KK, Gupta VK 2010. Synthesis and in vitro antibacterial activity of thymol and carvacrol derivatives. Acta Pol Pharm 67: 375-380.

Mikus J, Harkenthal M, Steverding D, Reichling J 2000. In vitro effect of essential oils and isolated mono- and sesquiterpenes on Leishmania major and Trypanosoma brucei. Planta Med 66: 366-368.

Moazeni M, Saharkhiz MJ, Hosseini AA 2012. In vitro lethal effect of a jowan (Trachysperm umammi L.) essential oil on hydatid cyst protoscoleces. Vet Parasitol 187: 203-208.

Monib MEM, Shaheen MS, Galal LA, Farrag HM 2010. Role of $T$. spiralis adult and larval antigens in immunomodulation of nitric oxide (NO) in intestinal and muscular phase of trichinelosis. Assiut Med J 34: 147-158.

Moreira DL, Teixeira SS, Monteiro MH, De-Oliveira AA, Paumgartten FJR 2014. Traditional use and safety of herbal medicines. Rev Bras Farmacogn 24: 248-257.

Nasrabadi NT, Mirghasemi N, Bakhtiari N, Zarrinkoub N, Mirghasemi N 2012. Comparison of anti-parasitic effects of garden thyme 
(Thymus vulgaris) extract and metronidazole on Trichomonas gallinae. RPS 7 (Suppl.): S788.

Nassef NE, El-Sobky MM, Afifi AF 2010. Worm and larval burden, histopathological and ultrastructural evaluation of $T$. spiralis vaccination using crude worms and/or larvae antigens: Experimental studies. PUJ 3: 27-38.

Pozio E 2007. World distribution of Trichinella spp infections in animals and humans. Vet Parasitol 149: 3-21.

Repetto G, del Peso A, Zurita JL 2008. Neutral red uptake assay for the estimation of cell viability/cytotoxicity. Nat Protoc 3: 1125-1131.

Santoro GF, das Graças Cardoso M, Guimarães LG, Salgado AP, Menna-Barreto RF, Soares MJ 2007. Effect of oregano (Origanum vulgare L.) and thyme (Thymus vulgaris L.) essential oils on Trypanosoma cruzi (Protozoa: Kinetoplastida) growth and ultrastructure. Parasitol Res 100: 783-790.

Shalaby MA, Moghazy FM, Shalaby HA, Nasr SM 2010. Effect of methanolic extract of Balanites aegyptiaca fruits on enteral and parenteral stages of Trichinella spiralis in rats. Parasitol Res 107: 17-25.

Sheir Z, Nasr AA, Massoud A, Salama O, Badra GA, El-Shennawy H, Hassan N, Hammad SM 2001. A safe, effective, herbal antischistosomal therapy derived from myrrh. Am J Trop Med Hyg 65: 700-704.
Shoheib ZS, Shamloula MM, Abdin AA, El-Segai O 2006. Role of $\alpha$-chymotrypsin and colchicine as adjuvant therapy in experimental muscular trichinellosis: parasitological, biochemical and immunohistochemical study. EJMM 15: 773-790.

Siriyasatien P, Yingyourd P, Nuchprayoon S 2003. Efficacy of albendazole against early and late stage of Trichinella spiralis infection in mice. J Med Assoc Thai 86 (Suppl.): S257-S262.

Ündeğer U, Başaran A, Degen GH, Başaran NN 2009. Antioxidant activities of major thyme ingredients and lack of (oxidative) DNA damage in V79 Chinese hamster lung fibroblast cells at low levels of carvacrol and thymol. Food Chem Toxicol 47: 2037-2043.

Yadav AK, Temjenmongla 2006. Anthelmintic activity of Gynura angulosa DC against Trichinella spiralis infections in mice. PhOL 2: 299-306.

Yadav AK, Temjenmongla 2012. Efficacy of Lasia spinosa leaf extract in treating mice infected with Trichinella spiralis. Parasitol Res 110: 493-498.

Zarrini G, Delgosha ZB, Moghaddam KM, Shahverdi AR 2010. Postantibacterial effect of thymol. Pharm Biol 48: 633-636.

Zeromski J, Boczoń K, Wandurska-Nowak E, Mozer-Lisewska I 2005. Effect of aminoguanidine and albendazole on inducible nitric oxide synthase (iNOS) activity in T. spiralis-infected mice muscles. Folia Histochem Cytobiol 43: 157-159. 